\title{
Finite element analysis of portal frame under fire condition
}

\author{
Dong Chen, Jinzhu Tang \\ School of civil engineering, Anhui Jianzhu University, Hefei 230022, China
}

\begin{abstract}
The steel structures are widely used in modern industrial factory due to its advantages such as high strength, good plasticity, good sealing property, and short construction period. However the poor fireresistance ability is the most significant weakness of the steel structures. The steel structure workshop is very easy to collapse and damage as long as the fire occurs. So it is very meaningful to study the collapse of steel structures under fire conditions. In this paper, one storey industrial factory buildings with light steel is used as an example and the influence of the intermediate support on the collapse of the steel structure is analyzed by using the finite element software ansys15.0. The damages of the structures are analyzed under the same temperature and load size of the structure. The results show that when the intermediate support is added in the workshop, it can effectively prevent the rapid collapse of the structure and delay the failure time of the structure. Therefore, increasing the intermediate support can effectively improve the overall stability of the structure and we should increase the intermediate support to the workshop in engineering practice.
\end{abstract}

KEYWORD: industrial factory, finite element, intermediate support, collapse

\section{INTRODUCTION}

With the rapid development of China's economy, the application of steel structure in construction is more and more widely, especially in the industrial plant and high-rise buildings. But the steel structure is very sensitive to fire, under the action of the fire, the yield strength and elastic modulus of steel will be reduced rapidly, which led to the continuous collapse of the steel structure (Li Kai, 2008), According to statistics, in the location of the fire statistics, the number of building fires up to the maximum number, within the scope of $35 \%$ in the world. The number of building fire casualties is the largest, accounting for the total number of casualties of the fire 90\% (Feng Yanping, 2009). According to analysis of major fire occurred throughout the country in 2000-2008(Li Haijiang, 2010): occurred in the plant, shopping malls, hotels, public places of entertainment heavy fire accounted for $58 \%$ of the total. In 1987 , the international organization for Standardization (ISO) gave the standard heating curve ISO-834 curve which was measured in a closed compartment with wood as fuel. That mathematical expression is expressed as:

$$
T=T_{0}+345 \log _{10}(8 t+1)
$$

Where $\mathrm{t}$ is heating time ( $\mathrm{min}), \mathrm{T}$ is $\mathrm{t}$ moment temperature $\left({ }^{\circ} \mathrm{C}\right), \mathrm{T} 0$ - initial temperature $\left({ }^{\circ} \mathrm{C}\right)$ usually is $20{ }^{\circ} \mathrm{C}$. There have been some research on the fire of steel structure in China. Yangfan (Yang Fan, 2010) simulates value to steel structure of large space and frame by the whole process of fire, which obtains the development of yield, the internal force redistribution and the change of support reaction force in the process of the fire. Ren Xuejun simulates value Steel and steel frame in fire. That gets the conclusion: for highrise steel structure, the fire occurred in the bottom frame room and middle span room even worse for the overall structure. So in practice, we should strengthen the protection of fire protection. If the fire occurred in the top or side of the room, only to the room or near the room, and the impact on the overall structure is not large, the fire protection can be properly reduced. Nonlinear finite element analysis of steel frame under high temperature by Yang Ning. It shows that the steel frame beam column joints and column base and other parts is the weak link of steel frame under fire, should strengthen the protection. Nonlinear finite element analysis of Portal frame under fire by Wang Hui. Finally the results are obtained: the structure of the refractory time and the critical temperature.

In this paper, taking a steel structure workshop as an example, the damages of the structures are analyzed under the same temperature and load size of the structure. 


\section{FINITE ELEMENT ANALYSIS MODEL.}

The model is a portal frame with 70 meters long, 30.8 meters wide and the column spacing is 7 meters. The floor plans of the factory with and without intermediate support are respectively shown in Figure 1 and 2. The column support layouts of $\mathrm{A} / \mathrm{B} / \mathrm{C}$ axis are shown in Figure 3.

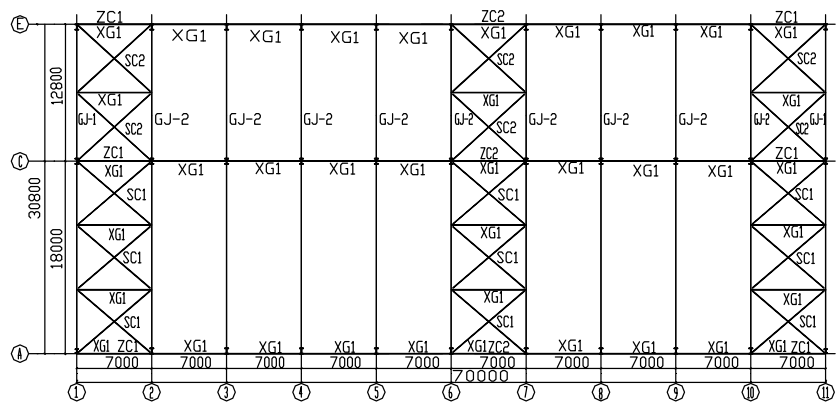

Fig. 1 Plan layout of workshop with intermediate support

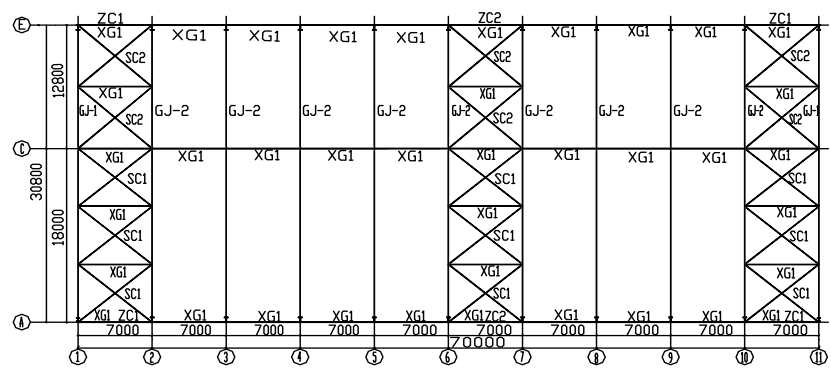

Fig. 2 Plan layout of workshop without intermediate support

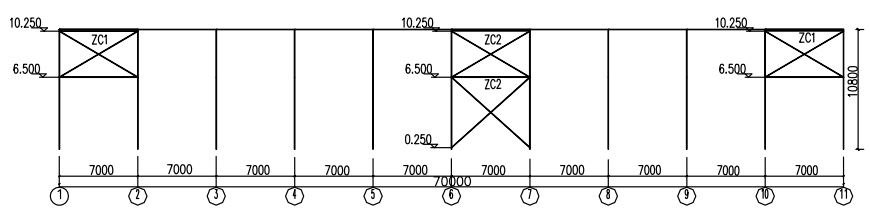

Fig. 3 Supporting layout diagram between pillars of $\mathrm{A} / \mathrm{C} / \mathrm{E}$ axis

Dead load of roof is $0.3 \mathrm{KN} / \mathrm{m} 2$, roof live load $0.5 \mathrm{KN} / \mathrm{m} 2$ and basic snow pressure $0.6 \mathrm{KN} / \mathrm{m} 2$. Q345 H type steel is used in Column, beam, intermediate support and other components. The section size of the column and the intermediate support is $500 \times 300 \times 10 \times 12$, and the cross section size of the beam is $500 \times 250 \times 10 \times 12$. The Lateral bracing is round steel with diameter of 20 and the inclined rod is a steel pipe with diameter of 140 and wall thickness of 4 .

The model uses ISO834 standard heating curve. The density of steel is $0.00785 \mathrm{~g} / \mathrm{mm} 3$. The specific heat capacity of steel varies with temperature, as shown in Figure 4. The elastic modulus of steel varies with temperature, as shown in Figure 5.The Poisson ratio is 0.3 . The coefficient of thermal expansion is $1.4 \times 10-5 \mathrm{~m} /\left(\mathrm{m} \cdot{ }^{\circ} \mathrm{C}\right)$. The heat transfer coefficient of steel varies with temperature, as shown in Figure
6.The stress-strain relationship of steel at different temperatures is shown in Figure 7.

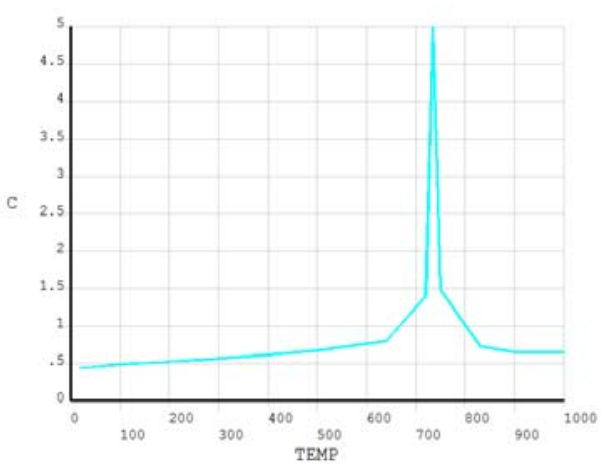

Fig.4 The curve of specific heat capacity with temperature

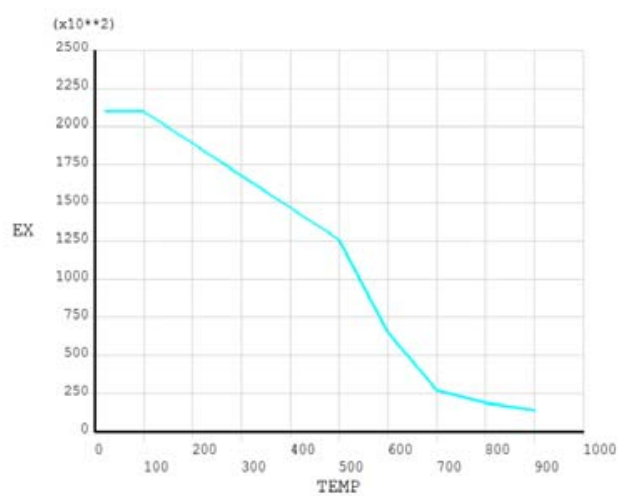

Fig.5 The curve of elastic modulus of steel with temperature

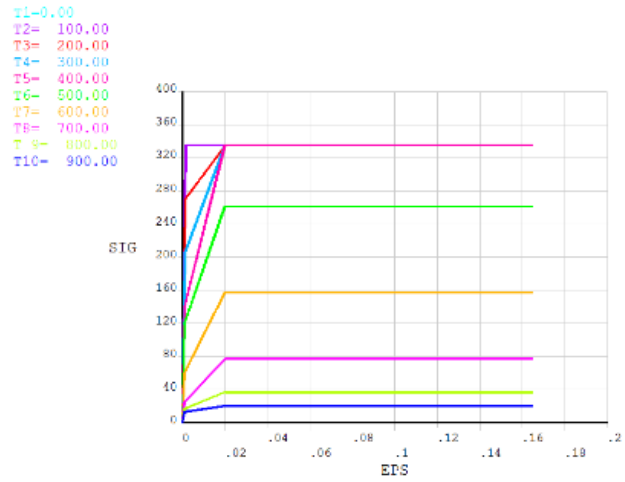

Fig. 6 The curve of thermal conductivity of steel with temperature

Failure criterion of steel structure:

(1) When the program do not restrain, the component should be judged invalid.

(2) The component should be judged invalid when the rate of the deformation bases on:

$\frac{d \delta}{d t} \geq \frac{l^{2}}{15 h}$

Where $\delta$ is the maximum deflection of members $(\mathrm{mm}), \mathrm{t}$ is the time of deformation $(\mathrm{h}), \mathrm{l}$ is the length of members $(\mathrm{mm}), \mathrm{h}$ is the height of member section $(\mathrm{mm})$. 


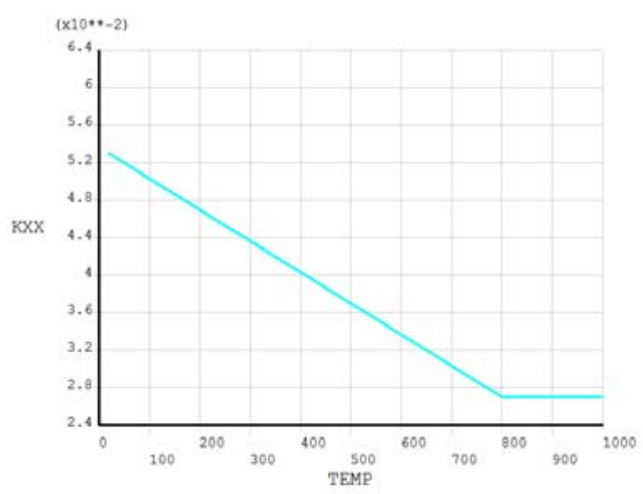

Fig. 7 The stress-strain relationship of steel at different temperatures

(3) The component should be judged invalid when the maximum deformation value exceed:

$$
\delta \geq \frac{l^{2}}{800 h}
$$

Where $\delta$ is the maximum deflection of members $(\mathrm{mm}), 1$ is the length of members $(\mathrm{mm}), \mathrm{h}$ is the height of member section ( $\mathrm{mm}$ ).

As is known to all, the whole structure of the progressive collapse is caused by the failure of the column, so this paper judges the whole structure failure by one or some columns' failure.

Two kinds of elements are used in this paper: solid70 unit and beam188 unit. Solid70 unit is adopted to rigid frame which is exerted temperature load and other steel columns, steel beams, inclined rods and horizontal supports are all beam 188 units. The first step in the analysis is thermal analysis, defining the physical unit. The subsequent analysis process is applying ISO standard heating curve to the surface of the solid element, converting thermal analysis into structural analysis, coupling the beam unit and the solid unit, Applying load on the basis of the analysis of the reheating and finally, the analysis results are obtained. The finite element models of rigid frame with intermediate support and rigid frame without intermediate support are shown in Figure 8 and 9.

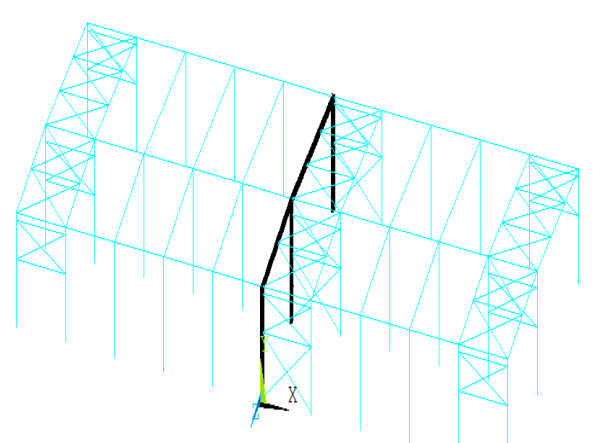

Fig.8 Finite element model of rigid frame with intermediate support

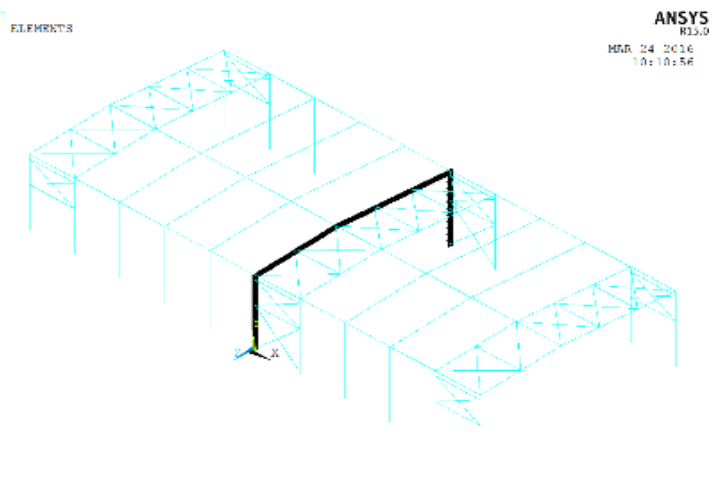

Fig.9 Finite element model of rigid frame without intermediate support

\section{CALCULATION RESULTS ANALYSIS.}

Table 1 The maximum von Mises stress values of GZ1 and GL1 (unit: mpa)

\begin{tabular}{ccc}
\hline component & $\begin{array}{c}\text { rigid frame without } \\
\text { intermediate support }\end{array}$ & $\begin{array}{c}\text { rigid frame with } \\
\text { intermediate } \\
\text { support }\end{array}$ \\
\hline GZ1 & 305.64 & 310.677 \\
GL1 & 234.39 & 310.678 \\
\hline
\end{tabular}

Table 2 The maximum deformation value of GZ1 and GL1 (unit: $\mathrm{mm})$

\begin{tabular}{ccc}
\hline component & $\begin{array}{c}\text { rigid frame without } \\
\text { intermediate support }\end{array}$ & $\begin{array}{c}\text { rigid frame with } \\
\text { intermediate support }\end{array}$ \\
\hline GZ1 & $\mathbf{2 9 9 . 1 2}$ & 223.80 \\
GL1 & $\mathbf{2 9 1 . 3 1}$ & 216.26 \\
\hline
\end{tabular}

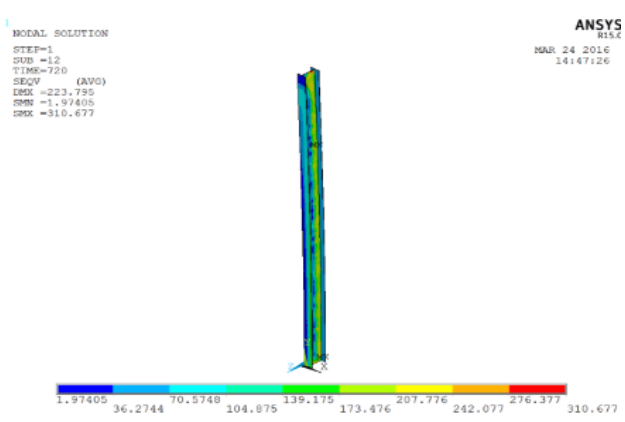

Fig. 10 Stress-deformation diagram of GZ1 with intermediate support

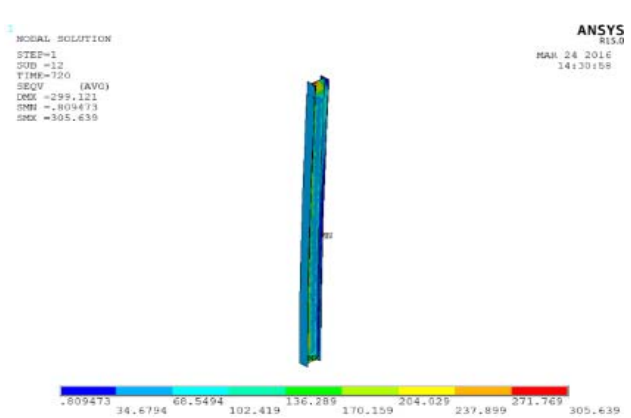

Fig. 11 Stress-deformation diagram of GZ1 without intermediate support 


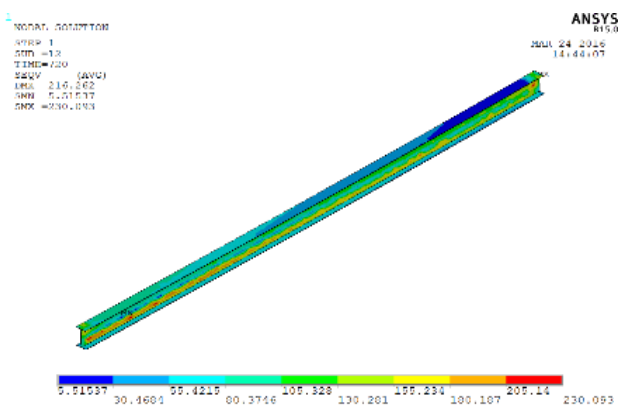

Fig. 12 Stress-deformation diagram of GL1 with intermediate support

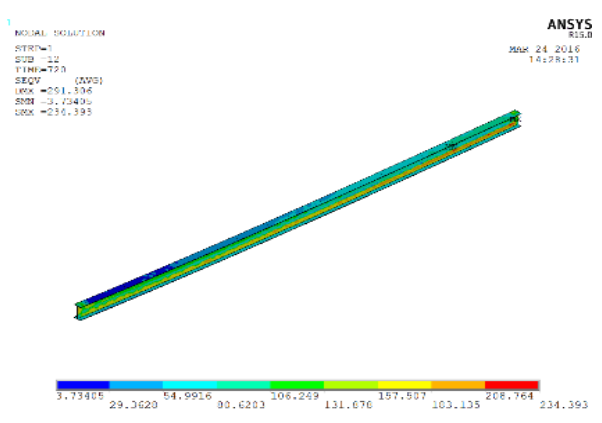

Fig. 13 Stress-deformation diagram of GL1 without intermediate support

The maximum allowable deformation of column is:

$\delta=\frac{l^{2}}{800 h}=\frac{10800^{2}}{800 \times 500}=291.6$

So the column will failure when the deformation of the column is more than $291.6 \mathrm{~mm}$. When the column fails, the whole structure is destroyed. The deformation of GZ1 without intermediate support has exceeded the maximum allowable deformation and the structure has been destroyed while the deformation of GZ1 with intermediate support has not exceeded the maximum allowable deformation and the structure has not been destroyed according to table 2, figure 10-13.

\section{CONCLUSION}

In this paper, one storey industrial factory buildings is used as an example to compare the damage between the rigid frame with intermediate support and the rigid frame without intermediate support by using the finite element software. The analysis shows that the rigid frame without intermediate support will collapse in the first place when it is subjected to fire under the same temperature and load conditions. Therefore, the intermediate support should be added in the design of the workshop.

\section{ACKNOWLEDGEMENTS:}

The authors sincerely thank the Nature Science Research Project of Anhui province (Research Project No. 1408085QE96) and Anhui universities natural science research project (Research Project No. KJ2015A046) for the financial support.

\section{REFERENCES}

Feng Yanping. The statistics of world's fire [J]. Firefighting technology and product information. 2009(3).

ISO. Fire Test of Materials and Structures [D]. Switzerland ISO n.d.1987.

Li Kai. Research on the method of calculating the progressive collapse resistance of the steel frame under fire [D]. Harbin Institute of Technology. 2008.

Li Haijiang. Statistical analysis of heavy and large fires in china during 2000-2008[J]. China Public Safety (Academic Edition).2010(3).

Ren Xuejun. Numerical analysis of steel and steel frame in fire behavior [D]. Hefei University of Technology.2007.

Yang Ning. Nonlinear finite element analysis of the steel frame under high temperature [D].Shandong University of Science and Technology.2011.

Wang Hui. Nonlinear finite element analysis of the portal frame structure under fire [D]. Wuhan University of Technology, 2009.

Yang Fan. The whole process of numerical simulation and damage assessment of large space and frame steel structure under fire [D]. Tsinghua University.2010 [D]. Tsinghua University. 2010. 